\title{
Analysis of capabilities of fiber separation in the existing parameters of the teeth profile of a disc saw
}

\author{
Akbar Abrorov*, Orzumurod Ikromov \\ Bukhara Engineering Technological Institute, Bukhara, Uzbekistan \\ *E-mail: abrorov1975@mail.ru
}

\begin{abstract}
The article covers the gripping capabilities of cotton fiber by tooth profiles of the disc saw. The working parameters between the teeth have been determined. The process of impact of cottonseeds on the saw teeth has been studied, as well as the regularity of the effect of the impact force on the saw tooth and on the indicators of the hardness of the seed shell have been determined.
\end{abstract}

Keywords: process of fiber separation, capture of cotton fiber, feather, fire bar, disc saw, saw teeth 


\title{
Анализ возможностей волоконотделения в существующих параметрах профиля зубьев дисковой пилы
}

\author{
Акбар Аброров*, Орзумурод Икромов \\ Бухарский инженерно-технологический институт, Бухара, Узбекистан \\ *E-mail: abrorov1975@mail.ru
}

\begin{abstract}
Аннотация. В данной статье показаны способности захвата хлопкового волокна профилями зубьев пильного диска. Определены рабочие параметры между зубьями. Изучен процесс ударного воздействия семян хлопчатника на зубья пилы и определена закономерность действия силы удара на зуб пилы и показатели жесткости оболочки семян.
\end{abstract}

Ключевые слова: процесс волокноотделения, захват хлопкового волокна, летучка, колосник, дисковая пила, зубья пилы

\section{1. Введение}

Процесс волокноотделения в волокноотделительных машинах происходит в результате захвата летучек с помощью зубьев пильного диска и транспортировки до рабочей части колосниковой решетки. В этом месте захваченные летучки притормаживаются, так как размер семян не позволяет пройти им через узкие межколосниковые зазоры, и от них происходит отрыв захваченных волокон вращающейся пилой. Все показатели процесса зависят от количества волокон, захваченных зубьями пил. Соответственно, в существующих параметрах профиля зубьев дисковой пилы анализируем основной показатель процесса волокноотделения - изменение производительности [1].

\section{2. Метод решения и результаты}

Пусть масса волокна, захваченного одной пилой в процессе, равна $\mathrm{m}_{\mathrm{o}}$ (г). Если число зубьев пилы равно z, число оборотов пилы равно n (об/мин), тогда производительность волокноотделительной машины за 1 мин:

$$
P_{m}=m_{O} \quad z n
$$

Если количество пил в пильном цилиндре обозначим через N, а производительность выражается в часах, тогда: 


$$
P_{m}=60 m_{O} \quad z n N
$$

Как правило, в хлопкоочистительных предприятиях средней мощности устанавливаются 2 волокноотделительных машины со средней производительностью 10 т/ч (10000 кг), тогда производительность одной машины составит 5 т/ч (5000 кг). Следовательно, учитывая, что в джинах марки ДП 130 пил, в каждом пильном диске по 280 зубьев, число оборотов 730 об/мин, определим:

$$
m_{O}=P_{m} /(60 z n N)=5000 /(60 \square 280 \square 730 \square 130)=3,14 \square 10^{-6} \kappa 2
$$

Соответственно, можно сказать, что при производительности джина 5 т/ч, на один его зубец приходится $3,14 \cdot 10^{-6}$ кг или $3,14 \cdot 10^{-3}$ г хлопкового волокна.

На рисунке 1 показан график зависимости массы волокна, соответствующего одному зубу, от производительности волокноотделительной машины и числа оборотов пильного цилиндра.

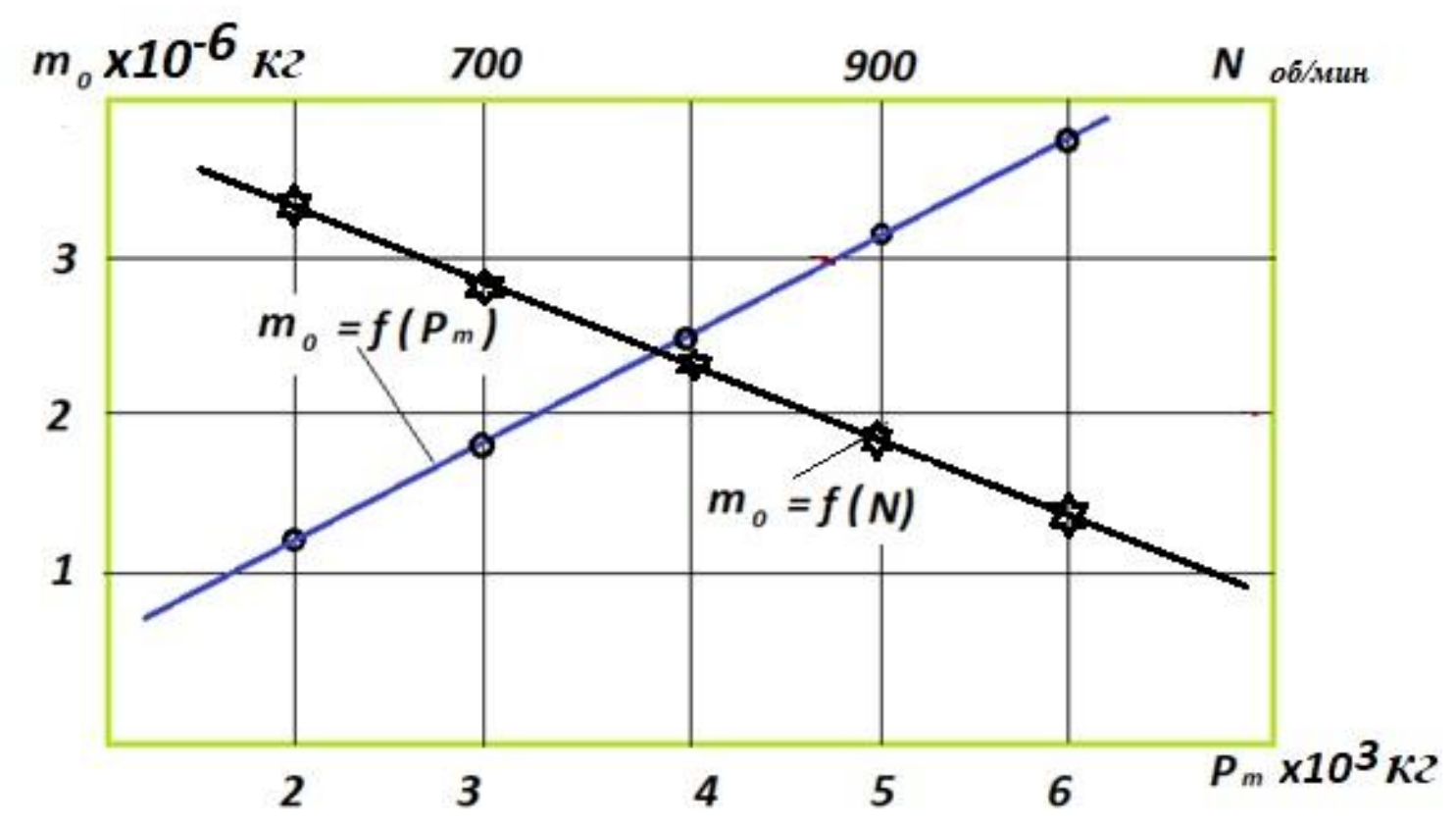

Рисунок 1. График зависимости массы волокна, соответствующего одному зубу, от производительности волокноотделительной машины и числа оборотов пильного цилиндра.

Соответственно, количество волокна на пилу увеличивается с увеличением производительности волокноотделительной машины и уменьшением числа оборотов пильного цилиндра, и, наоборот, количество волокна на пилу уменьшается с уменьшением производительности волокноотделительной машины и увеличением числа оборотов пильного цилиндра $[2,3]$. 
Это логически правильно. Следовательно, конечной целью производства является повышение общей производительности джина, а не количества волокна на зуб. Теперь посмотрим, какая часть пространства между зубьями пилы занята волокнами, прикрепленными к одному зубу пилы.

Согласно справочникам, 1 волокно средневолокнистого хлопка имеет массу $\mathrm{m}_{\mathrm{t}}=(0,5$ $0,6) \cdot 10^{-5}$ г. В этом случае количество волокон на зуб пилы равно:

$$
N_{t}=m_{O} / m_{t}=3.14 \square 10^{-3} /(0.5-0.6) \square 10^{-5}=523-628 \text { штукк. }
$$

Волокна, прикрепленные к пиле, находятся в положении пучка (рисунок 2). Постараемся определить поперечное сечение пучка и занимаемый им объем. Если диаметр пучка равен d, а длина L, тогда его объем равен:

$$
V=S L
$$
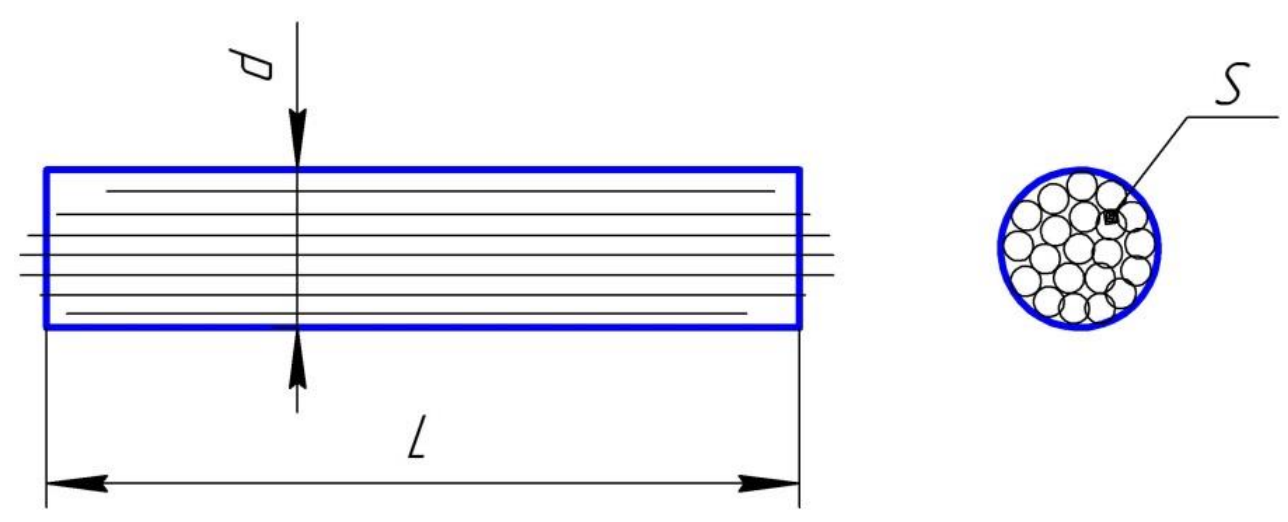

Рисунок 2. Схема определения площади поперечного сечения пучка волокон.

Диаметр одиночного волокна $\mathrm{d}_{\mathrm{t}}=15-25$ мкм, $2 \times 10^{-2}$ мм, площадь поперечного сечения:

$$
S_{t}=0,25 \pi d^{2}=0.25 \times 3,14 \times 4 \times\left(10^{-2}\right)^{2}=3,14 \times 10^{-4}{ }_{M M^{2}}
$$

Когда количество волокон в пучке равно N, площадь, занимаемая пучком, равна:

$$
S=k N S_{t}
$$

здесь $k$ - коэффициент заполнения площади поперечного сечения пучка волокон. Его значение больше 1 . Пусть $\mathrm{k}=1,25$. Согласно этому, принимаем:

$$
S_{t}=k N S_{t}=1,25 \times(628 \div 523) \times 3.14 \times 10^{-4}=0,25-0,21 \mathrm{M \mu}^{2} ; S_{t}=0,25 \mathrm{MM}^{2} \text {. }
$$

Мы предполагаем, что средняя длина волокна для средневолокнистых сортов хлопка L $=32$ мм. В этом случае

$$
V=(0,25 \div 0,21) \times 32=(6,72 \div 3,3) \mathcal{M M}^{3}
$$


Постараемся определить, сколько площади поверхности пучка волокон занимает пространство между зубьями пилы [4].

Пространство между зубьями пилы представляет собой треугольник. Определяем его поверхность. Для этого находим стороны треугольника на рисунке 3.

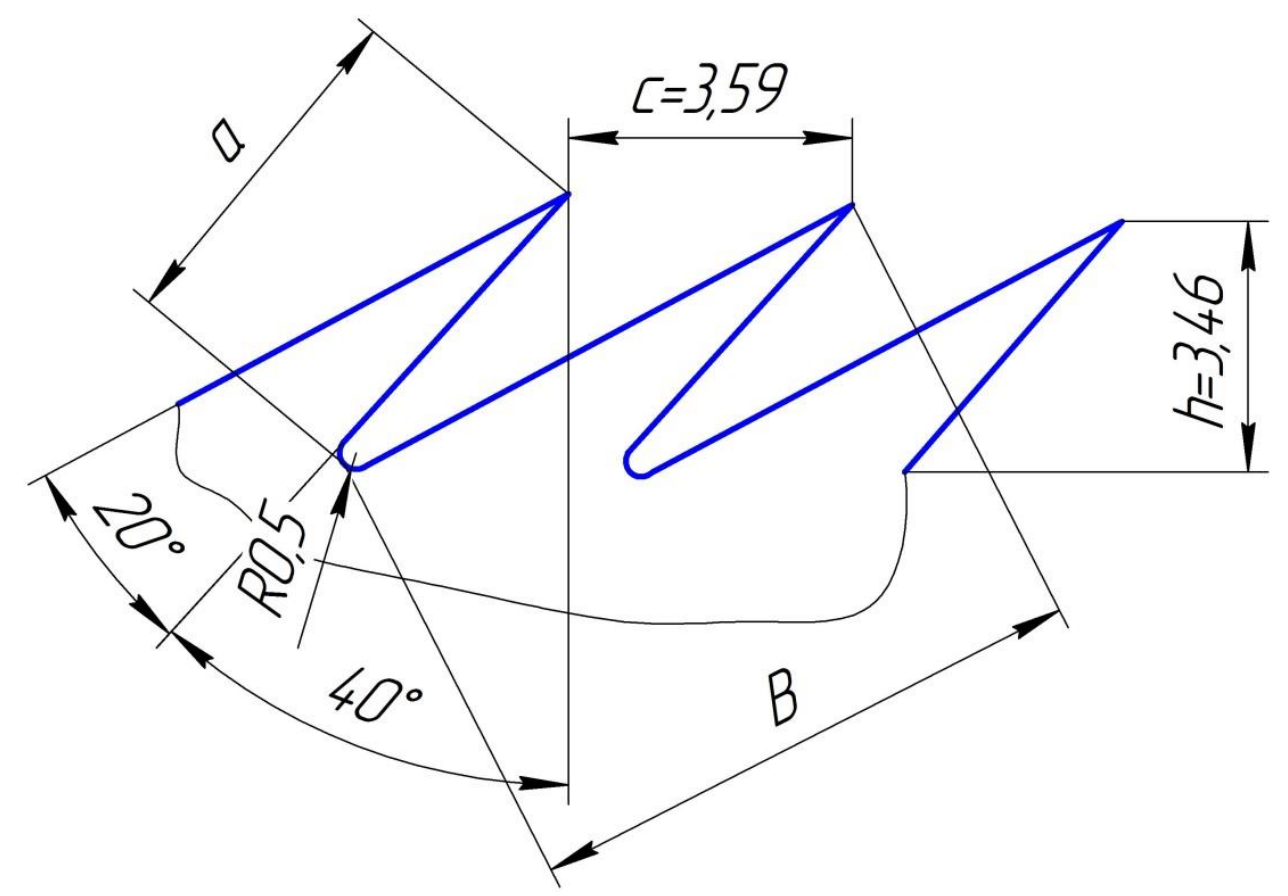

Рисунок 3. Схема определения площади между зубьями пилы.

$$
\begin{gathered}
b=\frac{h}{\cos 60}=\frac{3,46}{0,5}=6,92 \mathrm{MM}, \\
a=\frac{h}{\cos 40}=\frac{3,46}{0,77}=4,49 \mathrm{MM} .
\end{gathered}
$$

Определим грань треугольника, сторона которого известна, с помощью уравнения Герона:

$$
S=\sqrt{p(p-a)(p-b)(p-c)}=\sqrt{7,5(7,5-3,59)(7,5-6,92)(7,5-4,49)}=7,2 \text { мм }^{2}
$$

Здесь $p-$ полупериметр,

$$
p=0,5(a+b+c)=0,5(4,49+6,92+3,59)=7,5 \text { мм. }
$$

Коэффициент $e$, показывающий, какая часть площади между зубьями пилы занята пучком волокон, можно определить следующим образом:

$$
e=\left(S_{t} / S\right) \times 100 \%=(0.25 / 7.2) \times 100 \%=3.47 \%
$$

Это значение очень маленькое и указывает на то, что хлопковый пучок составляет лишь 1/29 площади между зубьями пилы. Это означает, что очень мало полезной площади между зубьями пилы работает, а большая часть остается пустой. Соответственно, можно сказать, что 
размер зубьев пилы получен с очень большим запасом, т.е. размер площади между зубьями велик и логичен для текущей производительности работы (например, 5 т/машинный час).

Однако эта мера приводит к уменьшению размера зубьев и значительно увеличивает шансы эффективного использования пилы. Как известно, актуален вопрос сохранения исходного качества изделий из хлопка в процессе пильного джинирования. Основная причина этого в том, что процесс джинирования осуществляется под сильными эффектами удара на сырье. В результате в семенах хлопчатника происходит механическое повреждение, включая раздавливание, разрыв, разрезание, размельчение, тогда как в волокне происходит укорачивание в результате разламывания и разрезания $[5,6]$.

В результате таких воздействий снижается качество хлопкового волокна и семян: уменьшается общее количество семян в результате измельчения, увеличивается степень их засоренности, снижается всхожесть из-за поломки семян, снижается урожай технических семян, уменьшается количество удаляемого шелухой семян волокна, увеличивается в нем показатель коротких волокон, увеличивается массовая доля примесей и дефектных соединений в волокне. В этом контексте необходимо в дальнейшем изучить явление ударов, которое вызывает повреждение семян и волокон. В рамках данной же работы на начальном этапе рассмотрено явление удара между зубьями пилы и семенами.

\section{3. Выводы}

При исследовании способности захвата хлопкового волокна профилями зубьев пильного диска определено, что в рабочих параметрах между зубьями только около 4\% площади было вовлечено в захват волокна, в то время как остальная часть оставалась пустой.

Изучен процесс ударного воздействия семян хлопчатника на зубья пилы и определена закономерность действия силы удара на зуб пилы и показатели жесткости оболочки семян.

\section{Список литературы}

[1] Мирошниченко, Г.И. и др. Оборудование и технология производства первичной обработки хлопка / Г.И. Мирошниченко и др. - Т., «Укитувчи», 1980. - с. 328.

[2] Abrorov, A. Method of thermal treatment of saw disk teeth of fiber-processing machines by laser quenching / A. Abrorov, M. Kuvoncheva, O. Rajabov, M. Mukhammadov, S. Jumaev // IOP Conference Series: Materials Science and Engineering. - 2020. - № 862. - 032034.

[3] Imomqulov, Sh. Influence to Optimization Geometric Parameter Saws on His (Its) Capacity to Work / Sh. Imomqulov, Z. Abduqahhorov // International Journal of Recent Technology and Engineering. - 2020. - № 9(1). - P. 1743-1753. 
[4] Imomqulov, Sh. Improvement Geometric Parameter Saws And Increasing His(Its) Capacity To Work / Sh. Imomqulov, Z. Abduqahhorov // International Journal of Engineering and Technology. - 2020. - № 12(3). - P. 503-507.

[5] Urinov, N. 2020 Technology of ionic-plasmic nitriding of teeths of disc saw of the knot of saw cylinder / N. Urinov, M. Saidova, A. Abrorov, N. Kalandarov // IOP Conference Series: Materials Science and Engineering. - № 734(1). - 012073.

[6] Саидов, Х. О рациональном профиле зуба джинной пилы / Х. Саидов // Журнал Янги техника, ГНТК УзССР по координации научно-исследовательских работ ТТИ. - 1963. - № 6. - C. 22-24. 